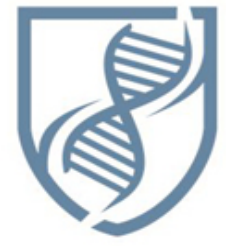

Journal of Bioscience and Applied Research

\section{JBAAR}

WWW.JBAAR.ORG

\title{
Effect of fast neutrons-irradiated diets on liver structure and function of male albino rats
}

\author{
Samir A. Nassar ${ }^{1}$, Mahmoud R. Mahmoud ${ }^{2}$, Magda S. Hanafy ${ }^{3}$ and Hagar A. Khalaf ${ }^{4}$ \\ 1, 2, 4: Zoology Department, Faculty of Science, Zagazig University, Egypt \\ 3: Physics Department (Biophysics), Faculty of Science, Zagazig University, Egypt
}

(Corresponding author: E-mail : $\underline{\text { samnas59@yahoo.com) }}$

\begin{abstract}
Presently, there is a growing need for the technology of food irradiation since it provides an effective process in food preservation and quality improvement . Accordingly, this study was designed to investigate the effects of fast neutron- irradiated wheat grains on the structure and function of the liver of albino rats. . Rats were categorized into two main groups (G1 \& G2),40 animals for each. Each group was subdivided equally to four subgroups ( $\mathrm{A}, \mathrm{B}, \mathrm{C} \& \mathrm{D}$ for $\mathrm{G} 1$ and $\mathrm{AA}, \mathrm{BB}, \mathrm{CC} \& \mathrm{DD}$ for $\mathrm{G} 2)$. $\mathrm{A}$ and $\mathrm{AA}$ served as control animals for G1 and G2 respectively and given non-irradiated diets, while B,C\&D were given irradiated diets at three different fluencies of fast

compared to controls . But, these little differences did not approaching a significant record except for ALP inBB subgroup of G2 . On histopathological examination of liver tissue, sporadic spontaneous lesions, known to occur in rats, were the only findings, with no specific relation to the studied stress factor. Therefore, it can be concluded that fast neutron-irradiated diets does not cause changes of any toxicological significance in experimental animals, at the conditions of the current experiment, in spite of minor changes in biochemical parameters . But, it is necessary to demonstrate the safety of radiationprocessed food in case of human consumption.
\end{abstract} neutrons; $4.3 \times 10^{5}, 2.0 \times 10^{6}$ and $1.4 \times 10^{7} \quad \mathrm{n} / \mathrm{Cm}^{2}$ respectively .But ,BB,CC and DD were given a diet of irradiated wheat of the second generation ( harvested from cultivation of the irradiated grains of the first generation ) at the same previous fluencies. Serum albumin and total protein, biochemical markers of liver function ( ALP, ALT and AST ) and the histopathological alterations of liver would be tested. Rresults of the present work highlight the detectable effect of irradiated wheat grains by the moderate $\left(10^{6}\right)$ and the highest $\left(10^{7}\right)$ fluencies of fast neutrons on albumin and total protein concentrations ( as indices of liver synthetic capacity). However the lowest $\left(10^{5}\right)$ fluency exerted no detectable effect. The application of feeding with grains of the $2^{\text {nd }}$. generation on G2 experimental subgroups ( BB, CC \& DD ) recorded a slight increase did not approaching a significant value $(\mathrm{p}>0.05)$ concerning albumin and total protein levels, in all treated animals Concerning the enzyme activities of alkaline phosphatase ( ALP ) and transaminases ( ALT \& AST ), they recorded minor fluctuations between the positive and negative range in the exposed animals of both groups ( G1 \& G2) as

Keywords: Fast neutron, Diet, Liver, Histology,

Enzymes, Rats

\section{Introduction}

Food irradiation is an applicable technology used in a large scale in Egypt to preserve and sanitize different types of economically-important crops and food stuffs by ionizing radiation. The main role played by this technology is to destroy the endogenous contamination of food arising from pathogenic bacteria, other harmful microorganisms, insects and parasites that may invade the food stuffs. However, the main problem of irradiation technology in food production is the safety of irradiated food to the public health since free radicals and their derivatives may be liberated and affect the living bodies (Sakaue et al., 1998, Wood\& Bruhn., 2000 \&Kume et al., 2009).

Ionizing radiation has been used safely to prolong the shelf life for more than 40 years, to improve the microbiologic safety, and to minimize the use of chemicals and additives in animal and human food stuffs ( 
Shea,2000). Others recorded a selective inactivating role for these radiations on pathogenic microorganisms and preserve the original qualities in irradiated food (Thayer and Boyd, 1993 \& Ahn and Nam, 2004). Feeding of albino rats on microwave heated food induced DNA damage ( in the nitrogen bases) as well as damage in the cell membranes of hepatocytes (Hajimehdipoor et al.,2006 and Verschaeve, 2009). Caulfield et al. (2009) recorded varying degrees of lesions and Wallerian degeneration in the brain and spinal cord of SPF cats after long-term feeding with gamma irradiated $(38.1-53.6 \mathrm{kGy})$ diets due to free radicals release. El-Shennawy (2013) recorded no effect on the physiological function of corn gluten (CG) after gamma irradiation at 8 and $10 \mathrm{kGy}$. Feeding this $\mathrm{CG}$ in rats decreased greatly the total cholesterol and lipid. Therefore, irradiated CG up to $10 \mathrm{kGy}$ may be used as a therapeutic strategy for the control and prevention of hyperlipidemia. An increase in the levels of proteins and concentrations of liver enzymes (ALP, ALT and AST) could be recorded by El Gazaly et al.,( 2014) in animals fed on microwave heated food at $2.45 \mathrm{GHz}$ for 8 week .

In a previous work for Hanafy and Mohamed (2014) ,the application of fast neutrons as ionizing radiation to irradiate the wheat grains( particularly at the neutron fluency of $2 \times 10^{6} \mathrm{n} / \mathrm{cm}^{2}$ ) prior to cultivation improved quantitatively and qualitatively the yield of wheat plant as a first part of a scientific project admitted by Zagazig University in 2010. The project was entitled: The use of fast neutrons to produce economically important genetic mutants of wheat crop. Therefore, the present study comes as a second part in the previous project to test the safety or toxicity of the resulted mutant of wheat grains for feeding to experimental animals to provide local scientific data base on safety and security purposes for this technology. Thus, the objective of this study was to evaluate the effect of fast neutron irradiated wheat grains resulted from two seasonal generations of cultivated wheat on the structure and function of liver of albino rats. To achieve this goal, liver was chosen as a target organ since it is a reactive one and a main organ responsible for metabolism and toxicity. So, serum levels of albumin, total proteins, liver enzymes and tissue histological changes of rat liver have to be tested.

\section{Material and Methods \\ 2.1.Plant material}

Wheat grains ( Triticum asetivum L.) were obtained from Agricultural Research Center, Dokki, Cairo, Egypt. The wheat cultivar Sakha 92 was chosen for this study because it is a global food crop particularly in Egypt.

\subsection{Animals}

Eighty(80) mature adult male albino rats (Rattus norvegicus) were used. Their weights ranged from 180-200 g each (3monthes age). Rats were categorized equally into two groups ( G1 \& G2 ) 40 animals for each. Animals $\mathbf{3} \mathbb{R 3}$ Results

G1 was subdivided B, C and D subgroups and those of G2 into BB, CC and DD subgroups.

\subsection{Irradiation}

Irradiation process was conducted in an irradiation facility at the Biophysics Department( Faculty of Science,
Zagazig University, Egypt) using The $\mathrm{Cf}^{252}$ point source $(\mathrm{E}=2.8 \mathrm{Mev})$ manufactured by Radiochemical Center, Amersham, England.

\subsection{Experimental design}

The grains (1600 g) were divided equally into 2 main groups ( G1 \& G2 ). Each group was subdivided equally to four subgroups (A, B, C\&D for G1 and AA, BB, CC \& DD for G2). Each of which contained $200 \mathrm{~g}$ grains. Grains of A and AA were kept unirradiated (control) for G1 and G2 respectively and fed to the matched groups of rats. Grains of B, C\&D were irradiated at three different fluencies of fast neutrons; $4.3 \times 10^{5}, 2.0 \times 10^{6}$ and $1.4 \times 10^{7}$ $\mathrm{n} / \mathrm{Cm}^{2}$ respectively and fed directly to the comparable subgroups of rats in G1. But, grains of BB,CC and DD were irradiated with the same previous doses and then soaked in water for $24 \mathrm{~h}$.for plantation to produce the second generation grains. The experimental work in the field was conducted in the period of 2011-2012. The product of wheat grain of the second generation (harvested from cultivation of the irradiated grains of the first generation) were collected, categorized and fed to the subgroups BB,CC and DD of G2 animals.

\subsection{Biochemical analysis}

After the end of each experimental period, animals were sacrificed, blood samples were collected and sera were separated to determine the albumin (Doumas and Watson,1971) and total protein (Henry,1974) concentrations. Liver enzymes were also calculated in sera to reflect the status of liver function. Alkaline phosphatase(ALP) was determined by Marsh et al. (1959) method, while liver transaminases (ALT and AST) were determined by Reitman and Frankel (1957) method.

\subsection{Histological studies}

Liver specimens from control and experimental animals were removed, fixed in $10 \%$ neutral formalin, dehydrated in graded ethanol, cleared in xylene, embedded in paraffin and then stained with hematoxylin and eosin (Bancroft and Gamble, 2002) to check the histological pattern of liver as affected by feeding with irradiated food. Collagen was also detected by Mallory's triple stain (Pearse, 1977). Sections were examined by light microscopy ( OPTECH, B3, CN:K7161, Germany ) and digitally photographed with a photomicrograph ( ProMicroscan, DEM 200 color CMOS Chip CE ).

\subsection{Statistical analysis}

Statistical analysis was done using analysis of variance (ANOVA), followed by t-test. Results were presented as means \pm standard deviation(SD). The value of $P<0.05$ was used to indicate statistical significance. Analysis was done using " Statistical Package for Social Sciences" (SPSS) version: 22.0 (IBM Corp., Armonk, NY, USA).

\subsection{Effect of feeding with irradiated wheat grains on serum albumin \&total protein levels in G1 and G2}

Serum concentrations of albumin and total proteins in G1 subgroups, as affected by feeding with irradiated diets, are presented in Table (1). Albumin level in G1 
treated animals recorded a slight increase in B subgroup with non-significant $(p>0.05)$ value, while C\& D subgroups afforded marked increase with significant $(\mathrm{p}<$ 0.05 ) values as compared to that of control (A) group. Total Protein level in B subgroup showed a slight decrease with non-significant ( $p>0.05$ ) value, while that of $C \& D$ recorded an obvious increase with significant $(\mathrm{p}<0.05)$ value. These results highlight the detectable effect of irradiated wheat grains by the moderate $\left(10^{6}\right)$ and the highest $\left(10^{7}\right)$ fluencies of fast neutrons on albumin and total protein concentrations ( as indices of liver synthetic capacity ). However the lowest $\left(10^{5}\right)$ fluency exerted no detectable effect.

The application of feeding with grains of the $2^{\text {nd }}$. generation on $\mathrm{G} 2$ experimental subgroups ( $\mathrm{BB}, \mathrm{CC} \& \mathrm{DD}$ ) recorded a slight increase did not approaching a significant value $(\mathrm{p}>0.05)$ concerning albumin and total protein levels, in all treated animals, as indicated in Table (2).

\subsection{Effect of feeding with irradiated wheat grains on liver function markers in G1 and G2:}

Serum ALP (indicator of bile duct injury) as well as transaminases ( ALT and AST ) of G1subgroups exhibited minor fluctuations with no statistically significant value ( $p$ $>0.05$ ) to record no effect for feeding with irradiated wheat grains on liver enzymes ( Table 3 ). Also, these liver function markers were unaffected $(\mathrm{p}>0.05)$ in all treated animals of G2 subgroups except those of CC subgroup which exhibited a significant $(\mathrm{p}<0.05)$ value for ALP ( Table 4).

\subsection{Effect of feeding with irradiated wheat grains on histological pattern of liver in G1 and G2}

The light microscopic examination of liver sections of the normal control animals exhibited a normal histological pattern for liver by $\mathrm{H} \& \mathrm{E}$ stain and normal collagen deposition in both of G1,A and G2, AA (Figs:1,2 \&9,10 respectively ). However, histological studies performed on liver tissue of experimental animals of G1 at the three different neutron fluencies $\left(10^{5}, 10^{6} \& 10^{7}\right)$ showed some histopathological alterations in the hepatic environment. These changes appeared as slight disorganization in the hepatic strands in animals received irradiated diets at $10^{5}$ fluencies (G1B, Figs: 3, 4) Irrespective of these alterations most of hepatocytes, kupffer cells and bile ductules appeared intact and exhibited a regular histological pattern. The application of feeding with irradiated diets at $10^{6}$ neutron fluency $(\mathrm{G} 1, \mathrm{C})$ resulted in less organized areas in the hepatic tissue and mild periportal lymphocytic infiltration (Fig: 5), while collagen deposition exhibited a slight increase around the portal area, (Fig.6).In spite of these minor changes, most of hepatic cords appeared regular. The liver tissue of animals fed irradiated diet at $10^{7}$ neutron fluencies (G1, D) exhibited a normal hepatic parenchyma except a low grade of disorganization in hepatic strand(Fig: 7) with one congested central vein and a relative increase in collagen deposition in the portal area, (Fig:8). No evidence of bile retention and fatty degeneration in hepatocytes in all treated subgroups of G1. Bile ducts and canaliculi were also normal in all experimental subgroups as confirmed by biochemical parameters (Tables:1,2). Investigating the effect of feeding with irradiated wheat grains (harvested from the cultivation of the first generation) to animals of G2 it does not exert adverse effects on the histology of the liver tissue. The liver of the normal control animals (AA) accompanying the experimental animals of the second group (G2) exhibited a normal histological and collagen pattern (Figs: 9, 10). At the lowest fluency $\left(10^{5}\right)$ animals of G2, BB revealed a low grade of focal necrosis in some hepatocytes in the periportal area, while others appeared normal with intact boundaries, together with mild lymphocytic infiltration, (Fig: 11). At the same time a relative increase in collagen deposition surrounding the elements of the portal area could be observed (Fig.12). At the moderate fluency $\left(10^{6}\right)$ feeding with irradiated diets (G2, CC) did not affect greatly the hepatic parenchyma which appeared organized with well- formed nuclei and healthy Kupffer cells except some lymphocytic infiltration and some apoptotic cells could be detected (Fig.13). Examination of Mallory-stained sections for the same animals confirmed the intact nature of hepatocytes and exhibited a collagen picture similar to that of the control ones (Fig. 14). Feeding of animals with irradiated diets $(\mathrm{G} 2, \mathrm{DD})$ at the highest fluency $\left(10^{7}\right)$ giving no affection the hepatic environment except some necrotic hepatocytes (Fig. 15) while other appeared normal. The reaction of the hepatic tissue to Mallory stain resulted in a collagen deposition more or less similar to their matched control and illustrated the good integrity of the cellular membranes. Some dilatation of blood sinusoids could be detected (Fig.16)

\section{Discussion}

The present study was an attempt to evaluate the effects of fast neutron- irradiation to wheat grains (an economically- important Egyptian crop ) on some biochemical parameters and the histological pattern of liver in albino rats to elucidate the safety of irradiated wheat grains, at certain neutron fluencies, for feeding to experimental animals.

In the current investigation, a significant increase in albumin and total protein concentrations in sera of animals fed irradiated diets in G1 was recorded, however in G2 the albumin and total protein levels were not affected. The authors considered this as a good index for liver synthetic capacity and an indication of no damage occurred to liver due to feeding with neutron-irradiated wheat grains. These observations extend and confirm those of Abul Hasanat et al. (2014) who reported that serum protein, albumin and globulin were significantly increased in animals fed irradiated diets. These higher values of serum 
Table(1): Albumin \& total protein concentrations in $\mathrm{mg} / \mathrm{dl}$ of male albino rats after feeding with irradiated wheat grains in subgroups of G1 under the effect of fast neutrons fluencies $\left(10^{5}, 10^{6} \& 10^{7} \mathrm{n} / \mathrm{cm}^{2}\right)$ as compared to that of the control.

\begin{tabular}{|c|c|c|c|c|}
\hline \multirow{2}{*}{ Parameters } & Control & \multicolumn{3}{|c|}{ Irradiated } \\
\cline { 2 - 5 } & $\mathrm{A}$ & $\mathrm{B}$ & $\mathrm{C}$ & $\mathrm{D}$ \\
\hline Albumin & $4.04 \pm 0.08$ & $4.06 \pm 0.07$ & $4.4 \pm 0.08$ & $4.5 \pm 0.06$ \\
\hline \%Change & & $0.49 \%$ & $8.91 \%$ & $11.39 \%$ \\
\hline P-Value & & 0.995 & $0.008^{*}$ & $<0.0001^{*}$ \\
\hline $\begin{array}{c}\text { Total } \\
\text { Protein }\end{array}$ & $6.87 \pm 0.8$ & $6.8 \pm 0.7$ & $7.12 \pm 0.848$ & $7.27 \pm 0.67$ \\
\hline \%Change & & $-0.29 \%$ & $5.01 \%$ & $7.23 \%$ \\
\hline P-Value & & 0.995 & $0.01 *$ & $<0.0001^{*}$ \\
\hline
\end{tabular}

*Significant value

Table(2): Albumin \& total protein concentrations in $\mathrm{mg} / \mathrm{dl}$ of male albino rats after feeding with wheat grains harvested from the irradiated grains of $1^{\text {st }}$ generation on G2 subgroups under the effect of fast neutron fluencies $\left(10^{5}\right.$, $10^{6} \& 10^{7} \mathrm{n} / \mathrm{cm}^{2}$ ) as compared to that of control.

\begin{tabular}{|c|c|c|c|c|}
\hline \multirow{2}{*}{ Parameters } & Control & \multicolumn{3}{|c|}{ Irradiated } \\
\cline { 2 - 5 } & AA & BB & CC & DD \\
\hline Albumin & $3.7 \pm 0.09$ & $4.2 \pm 0.12$ & $3.78 \pm 0.061$ & $3.9 \pm 0.08$ \\
\hline$\%$ Change & & $13.51 \%$ & $2.16 \%$ & $5.41 \%$ \\
\hline P-Value & & 0.997 & 0.361 & 0.999 \\
\hline Total Protein & $6.5 \pm 0.11$ & $6.9 \pm 0.15$ & $10.5 \pm 0.04$ & $6.6 \pm 0.09$ \\
\hline \%Change & & $6.15 \%$ & $61.54 \%$ & $1.54 \%$ \\
\hline P-Value & & 0.997 & 0.359 & 0.999 \\
\hline
\end{tabular}

Table(3): Alkaline Phosphate, AST \& ALT concentrations in mg/dl of male albino rats after feeding with irradiated wheat grains in G1 subgroups under the effect of fast neutrons fluencies $\left(10^{5}, 10^{6} \& 10^{7} \mathrm{n} / \mathrm{cm}^{2}\right)$ as compared to that of control:

\begin{tabular}{|c|c|c|c|c|}
\hline \multirow{2}{*}{ Parameters } & Control & Irradiated & \multicolumn{2}{c|}{ subgroups } \\
\cline { 2 - 5 } & $\mathrm{A}$ & $\mathrm{B}$ & $\mathrm{C}$ & $\mathrm{D}$ \\
\hline ALP & $399 \pm 11.41$ & $394.5 \pm 15.06$ & $433.7 \pm 39.87$ & $412.2 \pm 17.7$ \\
\hline \%Change & & $-1.13 \%$ & $8.70 \%$ & $3.31 \%$ \\
\hline P-Value & & 0.998 & 0.607 & 0.961 \\
\hline AST & $72.8 \pm 2.1$ & $77.4 \pm 3$ & $68.4 \pm 2.3$ & $74.6 \pm 2.3$ \\
\hline \%Change & & $6.32 \%$ & $-6.04 \%$ & $2.47 \%$ \\
\hline P-Value & & 0.454 & 0.086 & 0.839 \\
\hline ALT & $281.7 \pm 5.5$ & $271.6 \pm 6.4$ & $264 \pm 6.4$ & $287.1 \pm 3.9$ \\
\hline \%Change & & $3.58 \%$ & $6.28 \%$ & $1.92 \%$ \\
\hline P-Value & & 0.413 & 0.448 & 0.916 \\
\hline
\end{tabular}


Table(4): Alkaline Phosphate, AST \& ALT concentration in $\mathrm{mg} / \mathrm{dl}$ of male albino rats after feeding with irradiated wheat grains cultivated from the irradiated grains of $1^{\text {st }}$ generation in G2 subgroup under the effect of fast neutrons fluencies $\left(10^{5}, 10^{6} \& 10^{7} \mathrm{n} / \mathrm{cm}^{2}\right)$ as compared to that of the control.

\begin{tabular}{|c|c|c|c|c|}
\hline \multirow{2}{*}{ Parameters } & \multirow{2}{*}{ Control } & \multicolumn{3}{|c|}{ Irradiated } \\
\cline { 2 - 5 } & AA & BB & CC & DD \\
\hline ALP & $359.9 \pm 12.02$ & $377.2 \pm 6.61$ & $389.8 \pm 3.8$ & $380.7 \pm 6.2$ \\
\hline \%Change & & $4.81 \%$ & $8.31 \%$ & $5.78 \%$ \\
\hline P-Value & & 0.288 & $0.028 *$ & 0.164 \\
\hline AST & $30.7 \pm 1.3$ & $31.2 \pm 1.04$ & $30 \pm 1.11$ & $32.3 \pm 1.03$ \\
\hline \%Change & & $1.63 \%$ & $-2.28 \%$ & $5.21 \%$ \\
\hline P-Value & & 0.842 & 0.995 & 0.071 \\
\hline ALT & $185.8 \pm 6.04$ & $190.3 \pm 3.4$ & $186.9 \pm 3.8$ & $169.5 \pm 5.9$ \\
\hline \%Change & & $2.42 \%$ & $0.59 \%$ & $-8.77 \%$ \\
\hline P-Value & & 0.981 & 0.942 & 0.633 \\
\hline
\end{tabular}

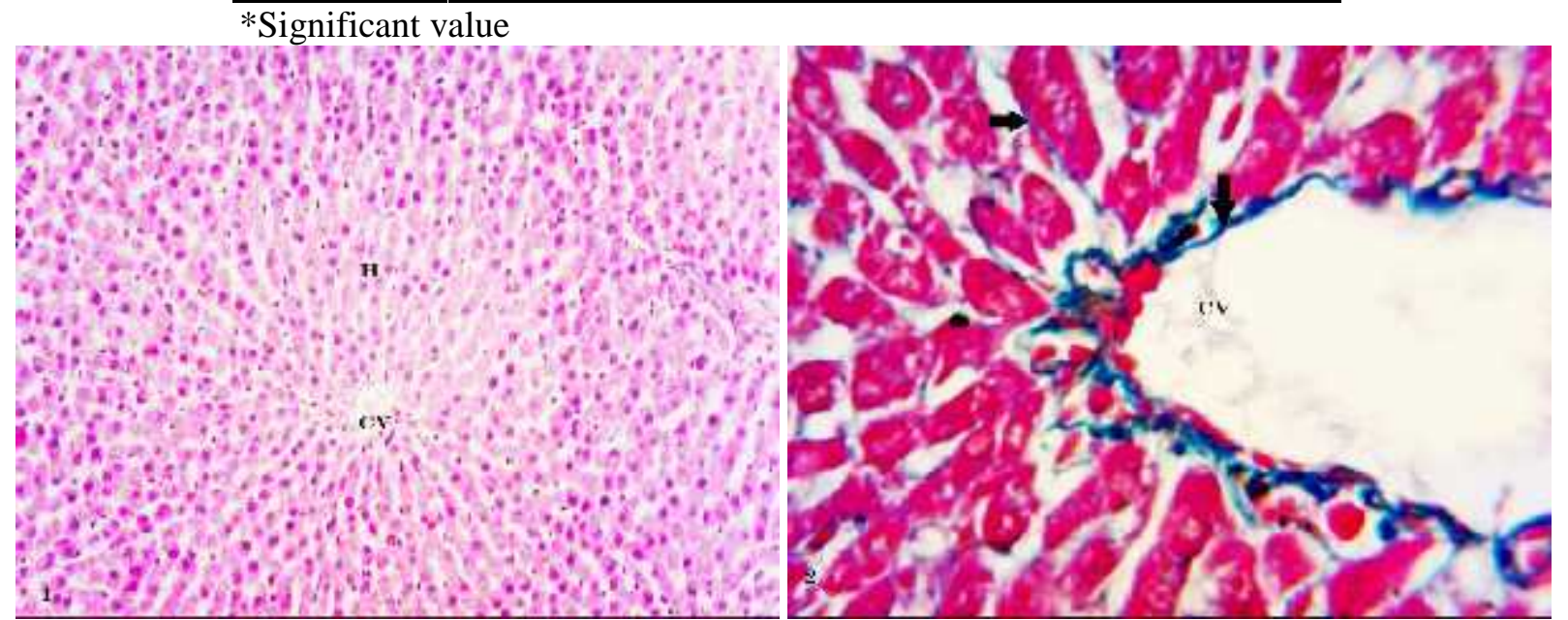

Fig (1): Section of liver of control animal (G1,A) stained with H\&E (X100) illustrating the normal histological structure of liver. Cords of hepatocytes $(\mathrm{H})$ radiating from the central vein $(\mathrm{CV})$.

Fig (2): A liver section of control rat (G1,A) stained with Mallory triple stain for collagen ( X 400 ) showing a normal collagen deposition $(\downarrow)$ observed surrounding the central vein $(\mathrm{CV})$ and blood sinusoids $(\rightarrow)$.

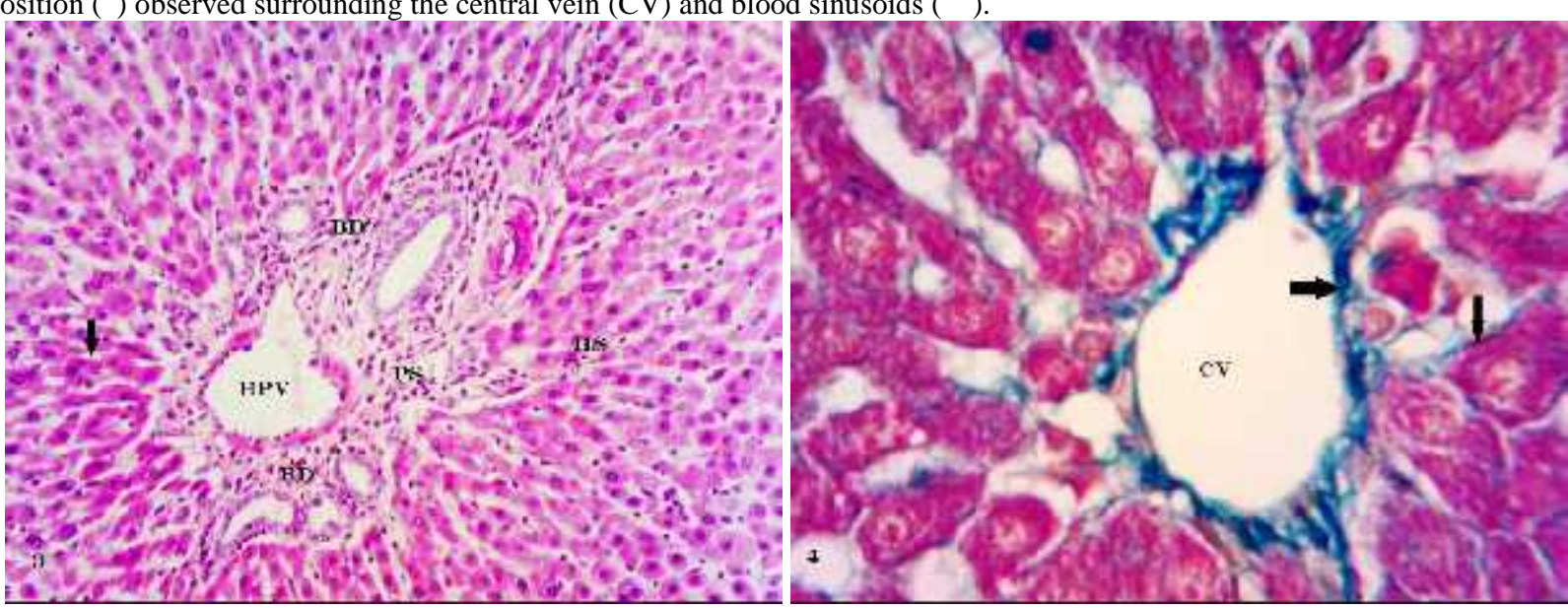

Fig(3): Sections of liver of treated animal(G1,B)stained with $\mathrm{H \& E}$ ( X100) showing a nearly normal histological pattern with a portal space (PS) comprising hepatic portal vein (HPV) and intact bile ductules (BD). Hepatic strands (HS) suffering from a slight disorganization ( $\downarrow$ ).

Fig(4): Section of liver of treated animal $(\mathrm{G} 1, \mathrm{~B})$ stained with Mallory triple stain for collagen(X400) showing a normal collagen deposition (thick and thin arrows) and a regular arrangement of hepatic cords around the central vein ( $\mathrm{cv}$ ) with intact hepatocytes. 


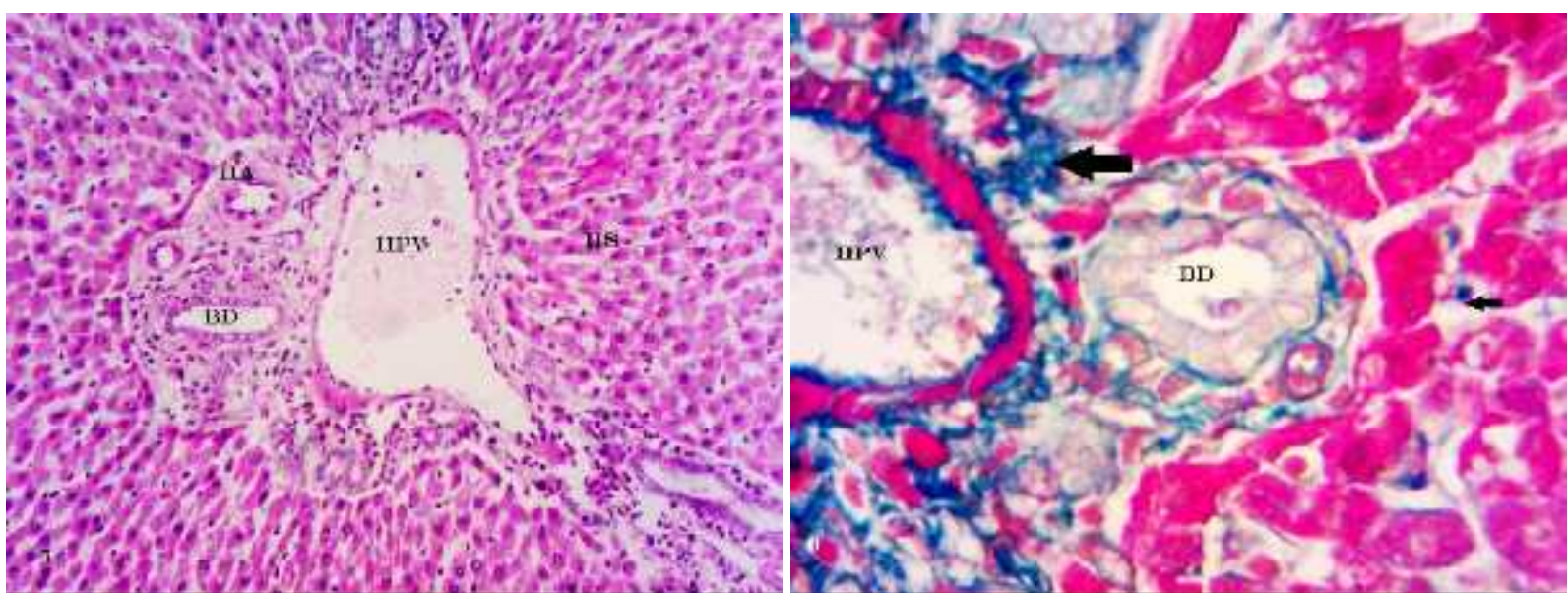

Fig (5): Section of liver of treated animal (G1,C) stained with H\&E (X100) illustrating portal space (PS)with its triad (HPV, BD, HA hepatic artery). Notice, the regular pattern of hepatic environment except some less organized hepatic strands ( HS ) and mild lymphocytic infiltration surrounding the elements of the portal area.

Fig(6): Section of liver of treated animal(G1,C) stained with Mallory triple stain for collagen (X400) showing intact hepatocytes a slight increase in collagen deposition (thick arrow) around the hepatic portal vein (HPV), bile ductules (BD) and blood sinusoids (thin arrow).
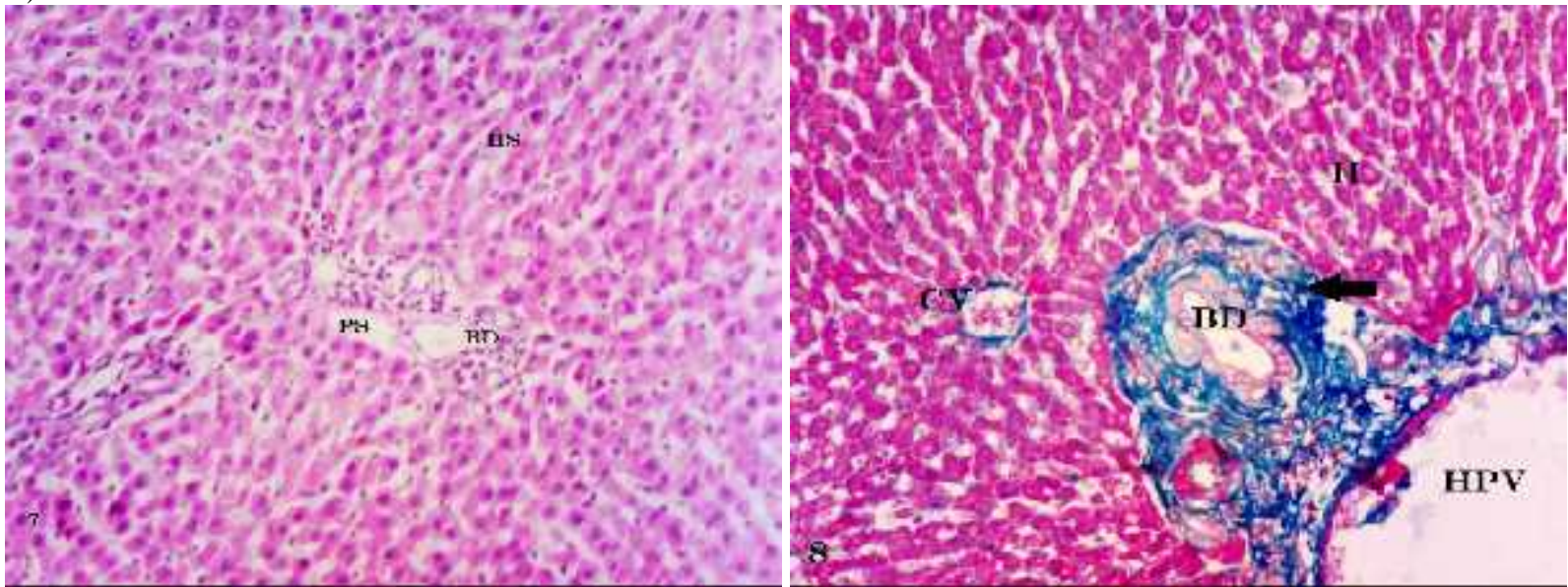

Fig (7): Section of liver of treated animal (G1, D) stained with H\&E (X100) showing an increased grade of disorganization in the hepatic environment (PS: portal space, BD: bile ductules, HS: hepatic strands).

Fig (8): Section of liver of treated animal (G1, D) stained with Mallory triple stain for collagen (X100) showing a moderate increase in collagen deposition around the HPV and BD, H: hepatocytes, CV:congested central vein.
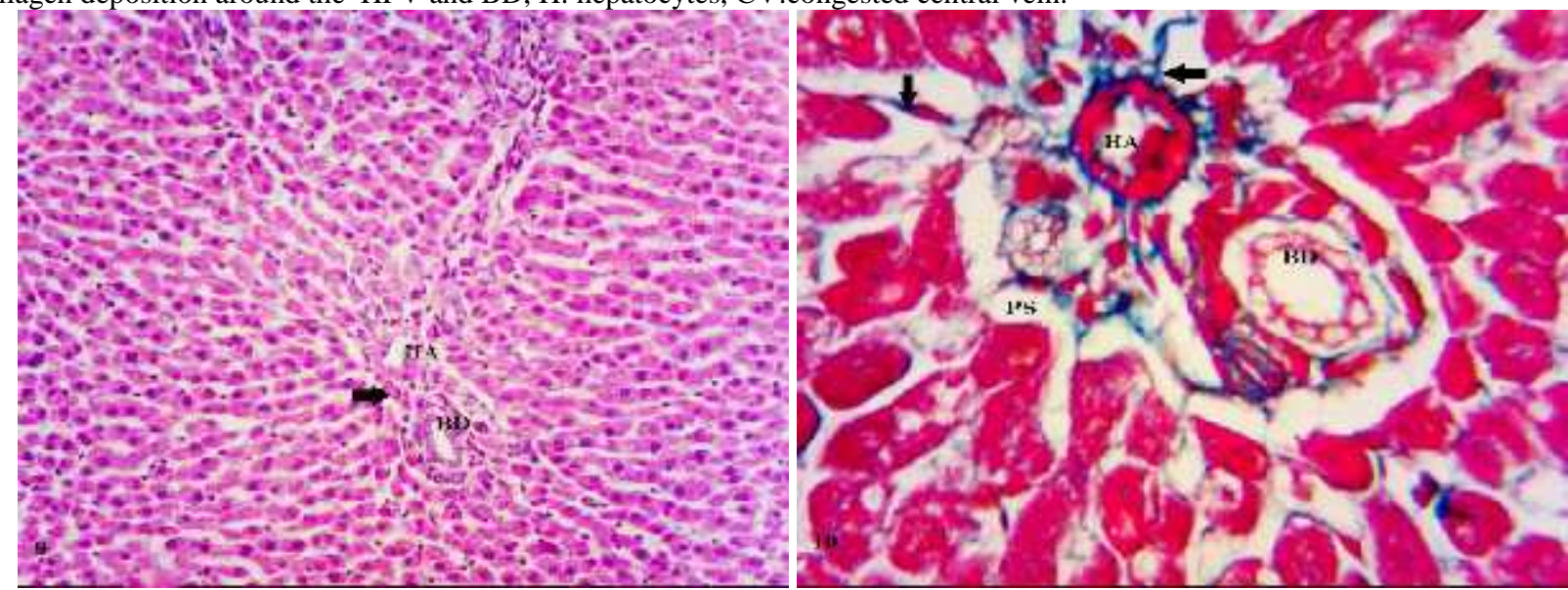

Figs(9): Sections of liver of control animal (G2,AA) stained with H\&E (X100) showing normal hepatic parenchyma,

HA: hepatic arteriole, BD: bile ductule.

Fig(10): Section of liver control animal (G2,AA) stained with Mallory triple stain for collagen (X400) revealing a normal deposition for collagen surrounding the hepatic arteriole $(\mathrm{HA} \leftarrow)$ in the portal space (PS) and blood sinusoids $(\downarrow)$. 

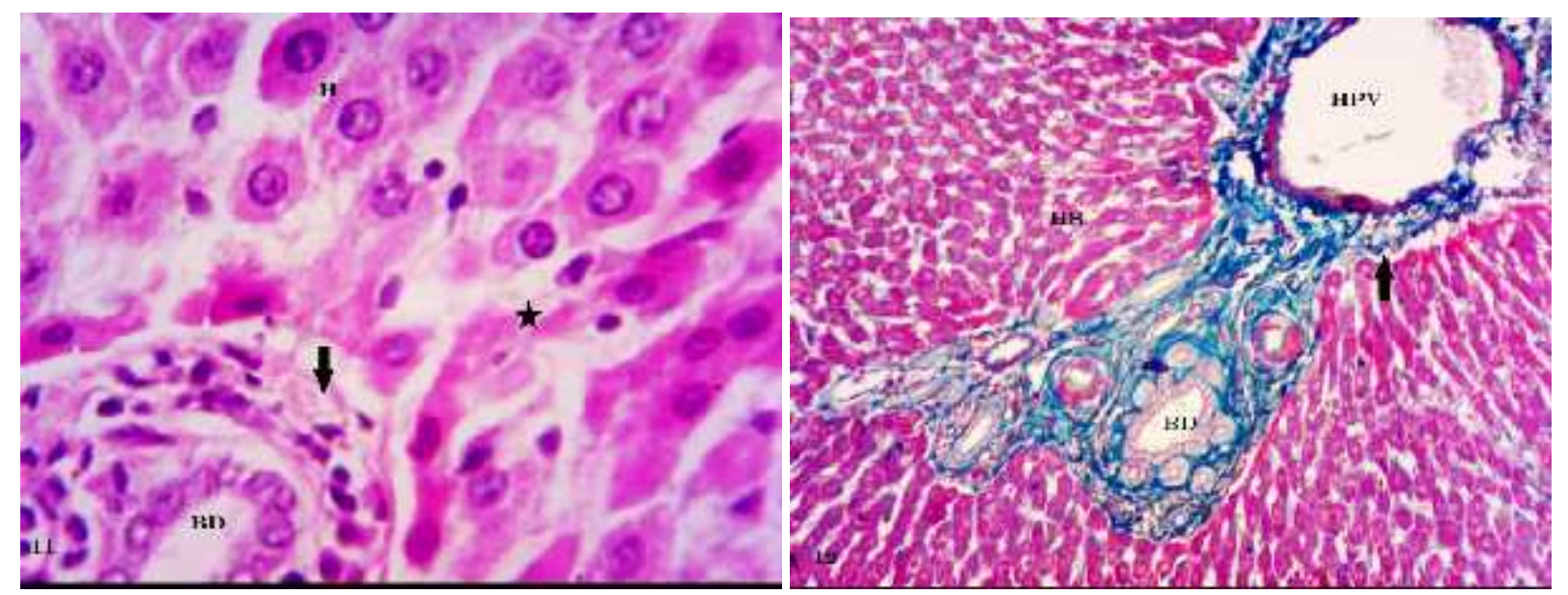

Figs(11):Section of liver of treated animal (G2,BB) stained with H\&E (X400) showing a hepatic parenchyma with low grade of focal necrosis $(*)$ in the periportal area together with mild lymphocytic infiltration $(\downarrow)$, other hepatocytes $(\mathrm{H})$ appeared normal with intact boundaries . BD; bile ductule, HPV: hepatic portal vein, HS: hepatic strands.

Fig (12): Section of liver of treated animal (G2, BB) stained with Mallory triple stain for collagen (X100) revealing increased collagen deposition (thick arrow) in the preiportal area (HPV, BD) and surrounding the hepatic arterioles and bile ductules. HS: hepatic strands.
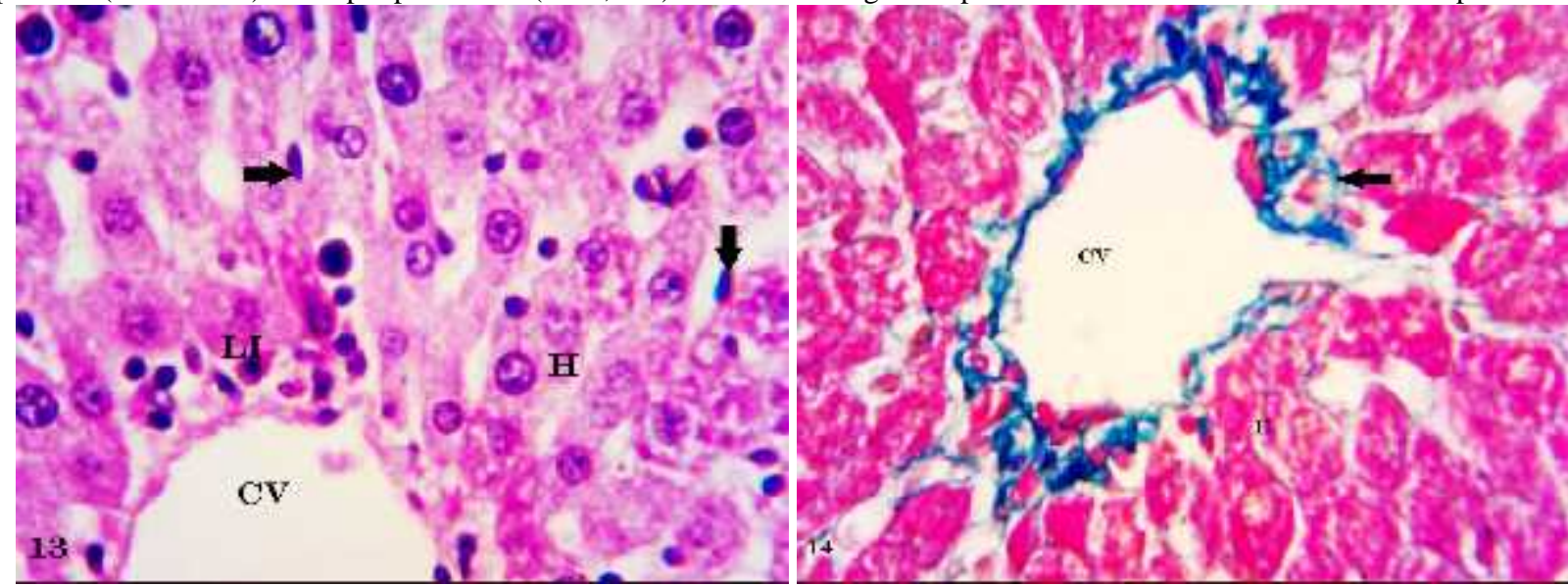

Fig(13): Section of liver of treated animal (G2,CC) stained with H\&E (X400)showing an organized hepatic parenchyma except some lymphocytic infiltration (L1) in the pericentral area $(\mathrm{CV})$ and some apoptotic cells $(*)$, other hepatocytes $(\mathrm{H})$ appeared normal with prominent nuclei and the Kupffer cells as well (arrows).

Fig(14): Section of liver of treated animal (G2,CC) stained with "Mallory triple stain" for collagen (X400)showing a collagen deposition similar to that of control animals (thick arrow) in the pericentral area (CV) and intact hepatocytes $(\mathrm{H})$.
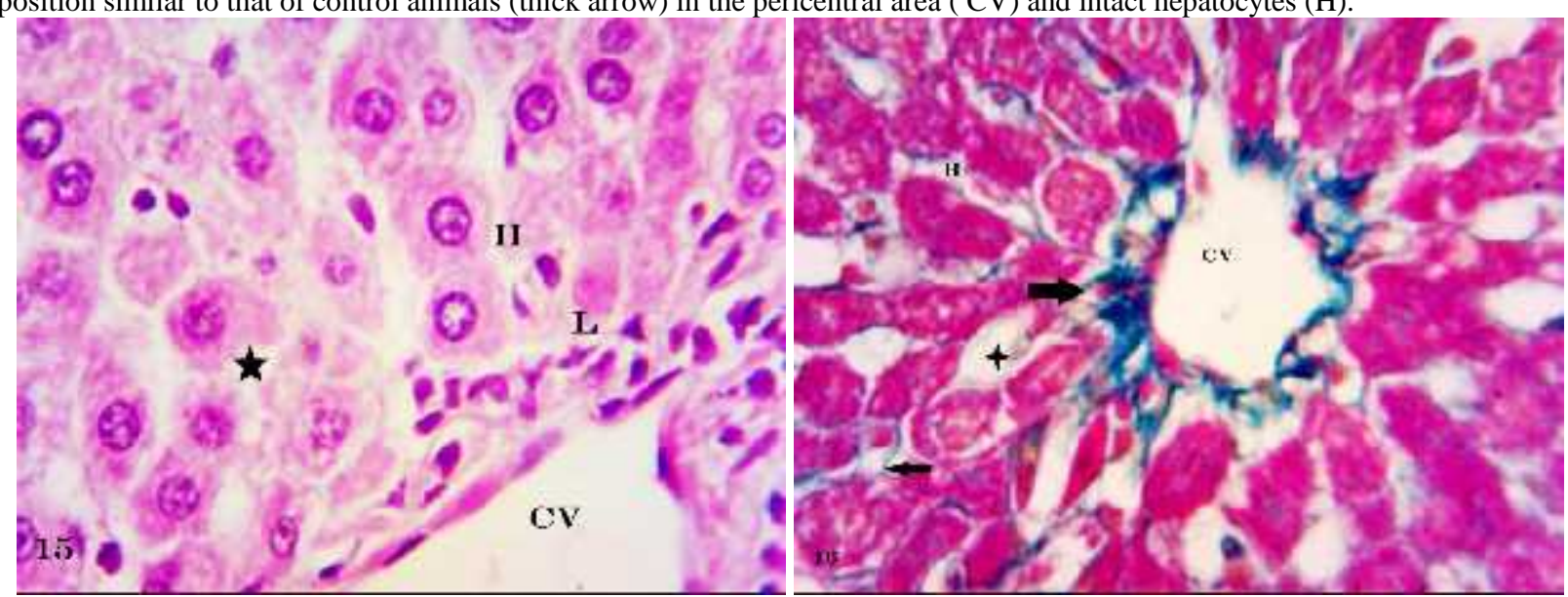

Fig(15): Section of liver of treated animal (G2,DD) stained with H\&E (X400)showing a hepatic parenchyma with focal necrosis $(*)$ in some hepatocyte, while others $(\mathrm{H})$ appeared normal to some extent. CV: central vein, L: lymphocytic infiltration.

Fig(16): Section of liver of treated animal (G2,DD) stained with "Mallory triple stain" for collagen (X400)showing a collagen deposition in the pericentral area (thick $\rightarrow$ ) and wall of blood sinusoids (thin $\leftarrow$ ) similar to that of the control.Notice, some dilatation in blood sinusoids $(*)$ 
protein and globulin in irradiated diet fed group reflected a healthy immune system in their animals and indicated no immunosuppressive effect of electron beam- irradiated diet on experimental animals. On the same bases El Ghazaly, et al (2014) recorded a statistically- significant increase in albumin levels of experimental group which fed on microwave heated food for 8 weeks. Kolawole, et al. (2015) recorded a significant $(\mathrm{p}<0.05)$ increase for albumin and globulin in rats fed with $\gamma$-irradiated millet. The authors reported that increased albumin concentrations may be beneficial and effective in regulating the colloidal respiratory pressure of blood, transport of fatty acid to the liver and an indication of no damage done to the liver by irradiated diets. They added albumin is a good predictor of health; low albumin level is a sign of deteriorated health and low globulin is an indication of liver dysfunction and antibody deficiency. Increasing albumin content in sera of experimental groups revealed that different types of protein compounds in irradiated foods become better digested than the non-irradiated ones (Koenari, et al. 2016). Wu, et al. (2016) recorded an improving effect for gamma irradiation at 5-15 KGy during the utilization of soybean as a fish meal substitute in diets for golden pompano. They added gamma irradiation induced changes in the molecular structure of proteins to inactivate the anti- nutritional factors (ANFs) in soybean as a meal. Other investigators recorded no significant alterations in total protein and albumin levels due to feeding with gamma-irradiated (10 KGy ) cotton seed meal (EL-Neily et al. 2013). Also, Hanafy and Mohamed (2014) studied the effect of fast neutrons from a $\mathrm{Cf}^{252}$ source in the fluencies range $10^{5}$ to $10^{6} \mathrm{n} / \mathrm{cm}^{2}$ on the Egyptian wheat cultivar (Sakha 92) and found that a low fast neutron fluency $2 \times 10^{6}$ increased the concentration of the total crude protein and proline amino acid. The results of the current experiment, also, extend and confirm previous similar results of Wong and Kitts (2002) who categorized gamma irradiation as a widely-used effective sterilization technology used for food, agriculture and hygienic products. However, Veneman et al. (2004) explained the elevation in the levels of albumin and bilirubin as a sort of liver cell damage after feeding mice on irradiated food.

Concerning the effect of feeding with irradiated wheat grains on liver enzymes (ALP, ALT and AST); the present data recorded no effect in all treated animals in G1 and $\mathrm{G} 2$, but just minor fluctuations in the up and down range with non-significant values. One exceptional case, which recorded a significant value for ALP, was the animals of subgroup BB in G2. These results stand side by side to those of albumin and total protein of serum to support the opinion of the present article that; feeding of experimental animals with fast neutron-irradiated wheat grains having no toxic effect. These results seem to be in agreement with a number of investigators and in contrary to others. Park, et al (2011) recorded a non- significant decrease in ALT \& AST values and increase in ALP value in ICR mice fed irradiated bulgogi as compared to the nonirradiated control. These results indicated that irradiated bulgogi did not show any subacute toxic effects under the experimental conditions. In addition, Rosen and Keeffe (2000) recorded that serum ALT \& AST are cytosolic enzymes of hepatocytes; an increase in their levels reflecting an increase in the plasma membrane permeability of hepatocytes which in turn associated with cell death. Gaskill et al. (2005) and Wu (2006) attributed the release of ALP, ALT and AST enzymes in blood stream to the damage which occurred in hepatocytes of the liver after feeding of experimental animals on microwave heated food. Hajimehdipoor, et al. (2006) reported that an increase in ALP and AST levels in blood serum after feeding on microwave food is not only an indicator for liver damage but also for other tissues. Furthermore, Fatemi et al. $(2010)$ recorded a significantly elevated $(\mathrm{P}<0.05)$ level for ALT and AST in rats fed g-irradiated caraway essential oils. The levels of ALT and AST increased about $223 \%$ and $215 \%$ respectively when compared to the control group.

The histopathological observation recorded in the current study which lacking the major pathological criteria but just sporadic spontaneous lesions, known to occur in rats, were the only findings with no specific relation to the studied stress factor confirmed our biochemical results. The recorded minor histopathological changes in the hepatic tissue appeared nearly similar in all treated animals of both G1 and G2, irrespective of the different neutron fluencies to which they are exposed. No treatment related histopathological changes were observed except the collagen deposition in the periportal area. The food items and their contaminants are absorbed in blood stream and pass to the liver via portal vein leading to such variations, particularly, in the periportal hepatocytes because they are the first lobular cells to receive. Therefore, the authors considered these changes to be episodic or adventitious ones due to the sensitive reactivity and response of hepatocytes to any toxicant or environmental pollutant since the liver is a target organ for contaminated food. This opinion is in agreement with other investigators (Maier et al.,1993; Thayer ,1994; Kang et al.,1998; WHO 1999; Hagiwara et al., 2005; Park et al., 2011; Irawati and Sani, 2012 and Kolawole, et al., 2015). Maier et al.(1993) examined the histopathological inspection of liver, kidney, lung, spleen thymus and DNA analysis of bone marrow cells and nuclei of hepatocytes of rats in response to feeding irradiated wheat and found no significant association with the feeding process. Thayer (1994) and Kang et al. (1998) studied the safety and nutritional adequacy of a variety of irradiated diets and recorded no toxic effects in experimental animals after feeding of irradiated food. WHO (1999) confirmed that feeding irradiated peaches (27.9 and $55.8 \mathrm{kGy})$ to Rhesus monkeys for two years, giving no adverse effects. Hagiwara et al. (2005) indicated that electron beamirradiated thaumatin does not exert any adverse effects on rats. They added no feeding- related histopathological alterations could be observed and considered all histopathological changes in their study as incidental onset. Park et al.(2011) observed no microscopical alterations in liver and kidney of ICR mice fed $40 \mathrm{KGy}$ - irradiated bulgogi. Irawati and Sani (2012) concluded that feeding of 
gamma irradiated food (45 kGy) in combination with packaging method of steamed gold fish, soy sauces beef and spicy curry beef to female rats, did not exhibit any pathological diagnosis nor clinical symptoms as compared to the un-irradiated food. Kolawole, et al. (2015) recorded that consumption of $\gamma$-irradiated millet by Wistar rats at different doses (2-8KGy) caused no detectable histopathlogical lesions or any deformity in the cells of liver, kidney, heart, brain, spleen and lungs. Also, Other investigators considered that irradiation ( 8 and10 $\mathrm{kGy}$ ) improves the physicochemical characteristics of food (Henry et al., 2001; Fan and Mastovska 2006; De Toledo et al. 2007; Gharaghani, et al. 2008; Ghanbari, et al. 2012 and El-Shenawy 2013). This phenomenon may be due to that radiation treatment reduced the quantities of crude fiber and increased the available carbohydrates of corn gluten (CG) thus improving its digestibility and induced breakdown of complex sugars into simpler ones. Other researchers reported that food irradiation does not destroy their protective role (Fatemi et al.,2010). The results confirmed the use of gamma-irradiation as a safe technique for preservation of herbal drugs. Koenari, et al. (2016) reported that irradiated ethnic RTE foods derived from animal origin at a dose of $45 \mathrm{kGy}$ and derived from plant origin at a dose of $8 \mathrm{kGy}$, , could be introduced to people who suffering from natural disasters to improve their nutritional status. In disagreement to the present results and other investigators, El-Gasaly et al. (2014) recorded several histopathological signs in liver of male mice (3 and 5 months age) after feeding on microwave heated food for 8 weeks. These lesions involved dilated and congested central veins, disappearance of normal blood sinusoids, cellular infiltration, foamy areas, sever degeneration of hepatocytes.

Therefore, it can be concluded that fast neutronirradiated diets does not cause changes of any toxicological significance in experimental animals, at the conditions of the current experiment ( doses lower than $10^{7}$ $\mathrm{nCm}^{2}$ neutron fluency), in spite of minor changes in biochemical parameters and histological pattern of liver .These results confirm the use of fast neutrons as a safe technique for food irradiation. But, it is necessary to demonstrate the safety of radiation-processed food in case of human consumption. subjects. The present study clearly indicated that fast neutrons irradiation is suitable for established diets safety. This suggests that the exposure of the experimental animals to feeding with fast neutronirradiated wheat grains does not affect greatly the liver function and histology to the degree of toxicity. But this must be taken in consideration when these results extrapolated to the human.

\section{References}

C F, Canniatti-Brazaca S G, Arthur V and Piedade S M S (2007): Effects of gamma radiation on total phenolics, trypsin and tannin inhibitors in soybean grains. Radiation Physics and Chemistry, 76: 1653-1656.

De Toledo T, C, F. Canniatti-Brazaca S, G. Arthur V and Piedade S, M, S. (2007): Effects of gamma radiation on total phenolics, trypsin and tannin inhibitors in soybean grains. Radiation Physics and Chemistry, 76: 1653-1656.

El-Ghazaly N, Kamel K, Radwan E H, Said H and Barakat A (2014): Impact of microwave heated food on health, Journal of Advances in Biology,5(3): 703-720.

El-Shenawy H M (2013): Effect of irradiated corn gluten on s.ome biochemical parameters of growing albino rats. Arab Journal of Nuclear Sciences and Applications, 46(5): 269-276.

El-Neily H F G D and El-Shenawy H M (2013): Effect of irradiated corn gluten on Some biochemical parameters of growing albino rats. Arab Journal of Nuclear Sciences and Applications , 46: 287- 299.

Fan X and Mastovska K (2006): Effectiveness of ionization radiation in reducing furan and acrylamide level in foods. Journal of Agriculture and Food Chemistry, 54: 8266-8270.

Fatemi F, Allameh A, Khalafi $\mathrm{H}$ and Ashrafihelan J (2010): Hepatoprotective effects of girradiated caraway essential oils in experimental sepsis. Applied Radiation and Isotopes, 68: 280-285.

Gaskill C L, Miller L M, Mattoon J S, Hoffmann W E, Burton S A and Gelens H C J(2005): Liver histopathology and serum alanine aminotransferase and alkaline phophatase activities in epileptic dogs receiving Phenobarbital. Veterinary Pathology, 42: 147-160.

Ghanbari F, Ghoorchi T, Shawrang P, Mansouri H \& Torbati-Nejad N M (2012): Comparison of electronbeam and gamma ray irradiations effects on ruminal crude protein and amino acid degradation kinetics, and in vitro digestibility of cotton seed meal. Radiation Physics and Chemistry, 81: 672-678.

Gharaghani H, Zaghari M, Shahhosseini G \& Moravej H (2008): Effect of gamma irradiation on antinutritional factors and nutritional value of canola meal for broiler chickens. Asian-Australasian Journal of Animal Sciences, 21: 1479-1485.

Hagiwara A, Yoshino H, Sano M, Kawabe M, Tamano S, Sakaue K, Nakamura M, Tada M, Imaida and Shirai k (2005): Thirteen-week feeding study of thaumatin (a natural proteinaceous sweetener), sterilized by electron beam irradiation, in Sprague-Dawley rats. Food and Chemical Toxicology, 43: 1297-1302.

Hajimehdipoor H, Sadeghi Z, Elmi S, Elmi A, Ghazi-Khansari M and Amanzadeh Y (2006): Protective effects of Swertia longifolia Boiss. and its active compound, swerchirin, on paracetamol-induced hepatotoxicity in mice. J Pharm Pharmacol, 58:277-280.

Hanafy M S and Mohamed H A (2014): Effect of irradiation of wheat grains with fast neutrons on the grain yield and other characteristics of the plants. Appl Radiat lsot., 86:71-78

Henry R G (1974): Clinical Chemistry. Chemicals and Technique. ( $2^{\text {nd }}$ Ed), Harper, New York., P.257.

Henry M H, Pesti C M, Bakalli R, Lee J, Toledo R T, Eitnmiler R R and Philips R D (2001):The performance of broiler chick fed diets containing extruded 
cotton seed meal supplemented with lysine. Poultry Science, 80: 762-768.

Irawati Z and Sani Y(2012): Feeding studies of radiation sterilization ready to eat foods on Sprague Dawley rats: In vivo. Natural Science, Vol.4, No.2: 116122.

Kang I J, Kwak H J, Lee B H, Kim K H, Byun M W and Yook H S (1998): Genotoxicological and acute toxicological safeties of gamma irradiated beef. Korean $\mathbf{J}$ Food Sci Technol, 30: 775-780.

Koenari Z I, Siagian C M, Simanungkalit B, Nilatany A, Pratama I M, Lasmawati D and Nurcahya C M (2016): Potential se of gamma-irradiated ethnic ready-toeat foods to improve the nutritional status of landslide victims. Foods, doi:10.3390/foods5030053; 5, 53.

Kolawole O. Falade , Omawumi B. Oweghoro , O. Taiwo Lasisi \& Ben O. Emikpe.(2015): Haematological, serum biochemical and tissue pathological changes induced by $\gamma$-irradiated millet. Comp Clin Pathol , 24:935-943.

Kume T, Furuta M, Todoriki S, Uenoyama N and Kobayashi Y(2009): Status of food irradiation in the world. Radiation Physics and Chemistry, 78: 222-226.

Maier P, Wenk-Siefert I, Schawalder H P, Zehnder H, Schlatter J (1993): Cell-cycle and ploidy analysis in bone marrow and liver cells of rats after longterm consumption of irradiated wheat. Food Chem Toxicol 31(6):395-405.

Marsh W H, Finger H B and Kirsch E (1959): Clin chem., 5:119-159.

Park J G, Kim J H, Byun M W, Jeon Y E, Kang J, Hwang H J and Ju Woon L J W (2011): Subacute toxicity study of $40 \mathrm{kGy}$ irradiated ready to eat Bulgogi .J Food Science and Nutrition, $16: 83-88$.

Pears A (1977): Histochemistry; Theoretical and Applied., $3^{\text {rd }}$ ed., Vol. 1. Churchill Livingstone, London.

Reitman S and Frankel S (1957): A colorimetric method for the determination of serum glutamic oxaloacetic and glutamic transaminase. Amer. J. Clin. Pathology, (28): 56-60.

Rosen H R and Keeffe E B (2000): Laboratory evaluation of the patients with signs and symptoms of liver disease. In: Brandt, L. J. (Ed.) Clinical practice of gastroenterology, 99: 812-820.

Sakaue K, Takeuchi M, Murata Y, Yoshifuji J, Hayashi $\mathrm{T}$ and Tada M (1998): Sterilization of proteinaceous food additives by irradiation: molecular alteration of plasma proteins by electron beam irradiation. Jpn J Food Chem, 5: 100-105. (in Japanese).

Shea K. (2000): Technical report: irradiation of food. Pediatrics, 106:1505-1510.

Thayer D W and Boyd G (1993): Elimination of Escherichia coli O157:H7 in meat by gamma irradiation. Appl Environ Microbiol, 59: 1030-1034.

Thayer D W (1994): Effect of gamma radiation on total tocopherols in fresh chicken breast muscle. Wholesomeness of irradiated foods. Food Technol, 14: 317-320.

Veneman T F Oude Nijhuis $\mathbf{J}$ and Woittiez A J (2004): Human albumin and starch administration in critically ill patients: A prospective randomized clinical trial. Wien Klin Wochenschr, 116:305-309.

Verschaeve L (2009): Genetic damage in subjects exposed to radiofrequency radiation. Mutat. Res, 681: 259-270.

WHO (1999): High-dose Irradiation: Wholesomeness of Food Irradiated with Doses Above 10 kGy: Report of a Joint FAO/IAEA/ WHO Expert Committee.World Health Organization, Geneva (WHO Technical Report Series, No.890).

Wong P Y Y and Kitts D D (2002): The effects of herbal pre-seasoning on microbial and oxidative changes in irradiated beef steaks. Food Chem, 76: 197-205.

Wood A B and Bruhn C M (2000): Position of the American Dietetic Association: Food irradiation. Journal of the American Dietetic Association, 100: 246(2)53.

Wu A H (2006): Tietz Clinical Guide to laboratory Tests, 4th ed.St.Louis:W.B.Saunders Company.

Wu Y, Ren G, Qin J G, Han $\mathrm{H}$ and Wang Y (2016): The suitable dose of gamma irradiation on soybean meal as a fish meal substitute in diets for golden pompano (Trachinotus ovatus). Aquaculture Research, 47: 19441953. 